\title{
Markers of Type I and Type III Collagen Turnover, Insulin-Like Growth Factors, and Their Binding Proteins in Cord Plasma of Small Premature Infants: Relationships with Fetal Growth, Gestational Age, Preeclampsia, and Antenatal Glucocorticoid Treatment
}

\author{
EERO KAJANTIE, TIMO HYTINANTTI, RIITTA KOISTINEN, JUHA RISTELI, \\ EEVA-MARJA RUTANEN, MARKKU SEPPÄLÄ, AND STURE ANDERSSON
}

The Hospital for Children and Adolescents [E.K., T.H., S.A.], and Department of Obstetrics and Gynecology [E.-M.R., R.K., M.S., S.A.], Helsinki University Central Hospital, Helsinki, Finland 00029 HYKS; Helsinki City Maternity Hospital, Helsinki, Finland 00600 [T.H.]; and Department of Clinical

Chemistry, University of Oulu, Oulu, Finland 90014 [J.R.]

\begin{abstract}
ABSTR
Disorders affecting fetal growth are commonly associated
with premature birth. IGFs and their binding proteins (IGFBPs)
are potent regulators of fetal growth. In vitro evidence suggests
that they regulate collagen turnover. Collagen turnover can be
monitored by serum markers of type I collagen synthesis (PINP)
and degradation (ICTP) and a marker of type III collagen syn-
thesis (PIINP). We examined whether these markers in fetal
circulation reflect intrauterine growth and maturity, and whether
any interrelationship exists between them and fetal IGFs and
IGFBPs in preterm infants before 32 wk of gestation. Cord
plasma PINP, ICTP, PIIINP, IGF-I, IGF-II, IGFBP-1, and IG-
FBP-3 were determined for 98 preterm infants. To express birth
weight in units adjusted for gestational age, a birth weight SD
score (SDS) was calculated. Negative correlations existed be-
tween gestational age and PINP $(r=-0.43 ; p<0.0001)$, ICTP
( $r=-0.34 ; p=0.002)$ and PIIINP ( $r=-0.34 ; p=0.0001)$.
Positive correlations existed between birth weight SDS and PINP
( $r=0.40 ; p=0.0002)$ and ICTP $(r=0.48 ; p<0.0001)$ but not
PIINP. Moreover, birth weight SDS was positively correlated
with IGF-I $(r=0.58 ; p<0.0001)$ and IGFBP-3 $(r=0.44 ; p<$
$0.0001)$ and negatively correlated with IGF-II $(r=-0.36 ; p=$
$0.003)$ and IGFBP-1 $(r=-0.50 ; p<0.0001)$ Gestational age
correlated with IGFBP-3 $(r=0.25 ; p=0.03)$ In preeclampsia,
IGF-I was lower $(p=0.002)$ and IGFBP-1 higher $(p<0.0001)$,
also after adjustment for fetal size. The number of antenatal
\end{abstract}
glucocorticoid treatments was associated with lower ICTP ( $p=$ $0.04)$, higher IGF-I $(p=0.002)$, lower IGF-II $(p=0.02)$, lower IGFBP-1 $(p=0.05)$, and higher IGFBP-3 $(p=0.004)$, also after adjustment for potential confounders. In multiple regression analysis, the factors significantly associated with PINP $\left(R^{2}=\right.$ $0.47)$ were gestational age and IGF-I, and those associated with ICTP $\left(R^{2}=0.54\right)$ were IGF-I, gestational age, and antenatal glucocorticoid treatment. We conclude that IGF-I may be involved in regulation of type I collagen turnover in the growing fetus. Cord blood PINP and ICTP reflect both fetal growth and maturity and deserve evaluation as potential indicators of postnatal growth velocity in preterm infants, whereas PIIINP reflects fetal maturity. (Pediatr Res 49: 481-489, 2001)
Abbreviations:
AGA, appropriate for gestational age
IGFBP, IGF-binding protein
ICTP, carboxyterminal telopeptide of type I collagen
INTP, aminoterminal telopeptide of type I collagen
PICP, carboxyterminal propeptide of type I procollagen
PINP, aminoterminal propeptide of type I procollagen
PIIINP, aminoterminal propeptide of type III procollagen
SDS, SD score
SGA, small for gestational age

Prenatal and postnatal growth restriction is a challenging problem in perinatology and neonatology. Normally the last

Received April 17, 2000; accepted October 25, 2000

Correspondence and reprint requests: Eero Kajantie, M.D., The Hospital for Children and Adolescents, Helsinki University Central Hospital, PL 280, FI-00029 HYKS, Helsinki, Finland; e-mail: eero.kajantie@hus.fi trimester of pregnancy is characterized by a significant increase in the velocity of fetal growth, regulated by IGFs and their

Supported by grants from the Academy of Finland, Finska läkaresällskapet, the Foundation for Pediatric Research, the Helsinki University Central Hospital Research Fund, and Wiipurilaisen osakunnan stipendirahastot. 
binding proteins (IGFBPs). They act via both endocrine and paracrine routes in promotion of cell proliferation and differentiation and in induction of protein synthesis (1). Collagens are the major connective tissue proteins, type I collagen being the only collagen found in mineralized bone and the most abundant collagen together with type III collagen, e.g. in skin, muscles, internal organs, and blood vessels $(2,3)$. The turnover of collagen is reflected in blood by markers of its synthesis and degradation. The markers of synthesis include the aminoterminal and carboxyterminal propeptides of type I procollagen, PINP and PICP, and the aminoterminal propeptide of type III procollagen, PIIINP. The markers of degradation include the aminoterminal and carboxyterminal telopeptides of type I collagen, INTP and ICTP (4).

Data on collagen turnover in the fetus are scarce. Cord blood PICP and ICTP (5) and the first postnatal urine INTP decrease with increasing gestational age, but no relationship with birth weight has been observed in term or near-term infants (6-8). PIIINP decreases toward term, reflecting fetal somatic growth velocity (9), and the PIIINP concentration has been lower in SGA than in AGA infants (10). During childhood, PICP and PIIINP reflect growth velocity (11).

Extensive data are available on the relationship of the fetal IGF system with fetal growth and maturity. Fetal IGF-I and IGFBP-3 are lower and IGFBP-1 higher in smaller infants (12-17), but data on the growth-regulating role of circulating IGF-II in the fetus are contradictory $(12-14,16)$. The IGFBP-1 concentrations are high also in the maternal circulation and amniotic fluid when the fetus is growth-retarded $(18,19)$. This may indicate that IGFBP-1 limits availability of free IGF-I in the fetus or at the fetomaternal interface where transfer of oxygen and nutrients takes place. In preeclampsia, both fetal and placental growth are often retarded, and both maternal and fetal IGFBP-1 are increased and IGFBP-3 is decreased (19-22).

In clinical practice, it is difficult to assess growth of sick premature infants, and biochemical growth markers would be useful. The use of IGFs and IGFBPs as such indicators is limited because they may be subject to measurement variation $(23,24)$. IGFs and IGFBPs regulate collagen synthesis and degradation in vitro (25-28), IGF-I administration increases collagen synthesis in adults (29), and pregnant women show a close correlation between IGF-I and PICP and PIIINP (30). Therefore, it is logical to examine whether markers of collagen metabolism would reflect growth and IGF and IGFBP action in the growing fetus and premature infant. This point has been highlighted by recent studies reporting a correlation between postnatal growth and PICP (31) and PIIINP (32). However, little is known about the relationship between the IGF system and collagen metabolism in premature infants.

With this background, we addressed the following questions. First, how do markers of type I and III collagen turnover and the IGF system in cord blood of premature infants relate to fetal growth and gestational age? Second, is there an independent interrelationship between these markers of type I and III collagen turnover and members of the IGF family, as suggested by results obtained in vitro and in vivo in studies in children and adults?

\section{METHODS}

\section{Study Population}

The 98 preterm infants (Table 1) born before 32 wk of gestation at the Department of Obstetrics and Gynecology,

Table 1. Clinical data and factors associated with prematurity

\begin{tabular}{|c|c|c|c|}
\hline Variable & All infants & Preeclampsia & $\begin{array}{c}\text { Antenatal } \\
\text { glucocorticoids used* }\end{array}$ \\
\hline $\mathrm{N}$ & 98 & 18 & 77 \\
\hline \multicolumn{4}{|l|}{ Gestational age (wk) } \\
\hline range & $24.1-32.0$ & $27.4-31.6$ & $24.3-32.0$ \\
\hline \multicolumn{4}{|l|}{ Birth weight (g) } \\
\hline mean \pm SEM & $1172 \pm 41$ & $1049 \pm 44$ & $1219 \pm 46$ \\
\hline mean \pm SEM & $-0.9 \pm 0.1$ & $-21 \pm 0.2$ & $-1.0 \pm 0.2$ \\
\hline range & $-5.0-+2.0$ & $-3.4-0.0$ & $-5.0-+2.0$ \\
\hline Male / female & $52 / 46$ & $11 / 7$ & $41 / 36$ \\
\hline Twins & 22 & 0 & 8 \\
\hline Triplets & 9 & 0 & 6 \\
\hline Small for gestational age $(<-2.0 \mathrm{SD})$ & 22 & 12 & 19 \\
\hline \multicolumn{4}{|l|}{ Cesarean section } \\
\hline After the onset of labor & 34 & 2 & 29 \\
\hline Without labor $\dagger$ & 27 & 16 & 24 \\
\hline Birth asphyxia (cord artery $\mathrm{pH}<7.15$ ) & 3 & 1 & 2 \\
\hline
\end{tabular}

* One treatment, 51 infants; two treatments, 20 infants; three treatments, three infants; four treatments, three infants.

$\dagger$ Clinical indications of cesarean section without labor included preeclampsia (16 infants), severe fetofetal transfusion (two infants), and other severe fetal growth retardation (five infants). 
Helsinki University Central Hospital, Helsinki, Finland, had their gestational age confirmed by ultrasound before $20 \mathrm{wk}$ of gestation. The study was approved by the Institutional Review Board of the Department of Obstetrics and Gynecology, Helsinki University Central Hospital.

\section{Birth Weight SDS and Placenta/Infant Weight Ratio}

The premature infants and their placentas were weighed immediately after birth. Because newborn length could not be recorded for all sick premature infants, it could not serve as a variable. To describe intrauterine growth in units adjusted for gestational age, a birth weight SDS was determined with reference to a Finnish newborn population of 74,766 singletons born from 1978 to 1982 (33). With infant birth weight, gestational age, and sex, each newborn infant's relative birth weight was expressed in birth weight SDS units. Because placental weight was closely correlated with birth weight SDS $(r=0.62$; $p<0.0001)$ and absolute birth weight $(r=0.55 ; p<0.0001)$, a placenta/infant weight ratio was calculated to express relative placental size.

\section{Clinical Data}

Clinical data came from hospital records. Preeclampsia was diagnosed on the basis of repeatedly elevated maternal blood pressure ( $\geq 140 / 90 \mathrm{~mm} \mathrm{Hg}$ or a $15 \mathrm{~mm} \mathrm{Hg}$ increase in diastolic and $30 \mathrm{~mm} \mathrm{Hg}$ increase in systolic blood pressure) and proteinuria ( $\geq 0.3 \mathrm{~g} / 24 \mathrm{~h})$. No mother received magnesium sulfate. Amnionitis was diagnosed on the basis of maternal or fetal tachycardia, fever, leukocytosis, and elevated serum C-reactive protein. Maternal labor was not used as a variable because the heterogeneous clinical characteristics of the nonlabor group (Table 1) would have been likely to mask the possible effects of labor itself. For the fetal blood gas analysis, a heparinized syringe was used to aspirate blood from a single artery of a double-clamped cord immediately after birth. Cord artery base excess rather than $\mathrm{pH}$ was used as a variable in the data analysis because it gives a more specific estimate of metabolic acidosis possibly associated with tissue hypoxia.

Betamethasone (12 mg intramuscularly twice at 12 -h intervals, treatment repeated in 7 to $10 \mathrm{~d}$ ) served as an antenatal glucocorticoid treatment when preterm birth was imminent between 24 and 32 wk of gestation (Table 1). The number of treatments ( 0 if no betamethasone) was used as a variable in the data analysis.

\section{Biochemical Analyses}

Blood sampling. Blood samples from the umbilical vein were drawn into EDTA-containing tubes, which were spun at $1000 \times g$ for $5 \mathrm{~min}$, with plasma stored at $-20^{\circ} \mathrm{C}$ until analysis. Because of the small volume of some blood samples, not all assays could be performed for all infants (Table 2).

PINP, ICTP, and PIIINP assays. The intact PINP, ICTP, and intact PIIINP concentrations were determined by specific RIAs against human antigens (Orion Diagnostica Ltd, Espoo, Finland). Of the several assays developed to assess degradation of type I collagen (4), we chose the serum assay for ICTP.
Table 2. Concentrations of biochemical factors

\begin{tabular}{llc}
\hline Factor & $\mathrm{N}$ & Concentration $(\mu \mathrm{g} / \mathrm{L})$ \\
\hline PINP & 82 & $2956 \pm 223$ \\
ICTP & 82 & $153 \pm 7$ \\
PIIINP & 82 & $215 \pm 23$ \\
IGF-I & 62 & $27.1 \pm 2.4$ \\
IGF-II & 69 & $523 \pm 40$ \\
IGFBP-1 & 77 & $297 \pm 61$ \\
IGFBP-3 & 77 & $1110 \pm 42$ \\
\hline
\end{tabular}

Results are mean \pm SEM.

ICTP is destroyed by cathepsin $\mathrm{K}$, which is active during normal bone resorption. This assay thus most likely reflects the matrix metalloproteinase pathway of type I collagen degradation (34). Inter- and intraassay coefficients of variation for the ICTP assay vary in six different concentrations between 4.1 and $7.9 \%$ and 2.8 and $6.2 \%$, respectively. The same figures for four different concentrations in the intact PINP assay are $3.1-8.2 \%$ and $4.8-13.7 \%$, and for the intact PIIINP assay, $4.1-18.0 \%$ and $4.4-6.4 \%$, respectively. The detection limits of these assays are PINP, $2 \mu \mathrm{g} / \mathrm{L}$; ICTP, $0.5 \mu \mathrm{g} / \mathrm{L}$; and PIIINP, $0.2 \mu \mathrm{g} / \mathrm{L}$.

IGF-I, IGF-II, IGFBP-1, and IGFBP-3 assays. The IGFI-concentrations were determined by ELISA (Diagnostic Systems Laboratories, Webster, TX, U.S.A.). Inter- and intraassay coefficients of variation are $8.8 \%$ and $7.1 \%$, respectively. The detection limit of this kit is $6.5 \mu \mathrm{g} / \mathrm{L}$. The IGF-II concentrations were measured by competitive immunofluorometric assay as described (35). Inter- and intraassay coefficients of variation were $4.9-13 \%$ and $7.2-8.6 \%$, respectively, and the detection limit was $120 \mu \mathrm{g} / \mathrm{L}$. The IGFBP-1-concentrations were determined by immunoenzymometric assay as described (36). Interand intraassay coefficients of variation were $7.4 \%$ and $3.4 \%$, respectively, and the detection limit was $0.4 \mu \mathrm{g} / \mathrm{L}$. The IGFBP-3 concentrations were determined with immunofluorometric assay as described (37). Inter- and intraassay coefficients of variation were $4.9-11 \%$ and $3.6-6.2 \%$, respectively, and the detection limit was $0.3 \mu \mathrm{g} / \mathrm{L}$.

\section{Data Analysis}

The results are mean values \pm SEM. Logarithmic transformation was used to normalize the data when appropriate. Correlations between the variables were estimated with simple linear regression analyses, and multiple stepwise linear regression was calculated by use of all variables with significant univariate correlation $(p<0.05)$ to determine which of the determinants had predictive values for the dependent determinant. When two groups were studied, $t$ test for unpaired samples was applied. The difference was considered significant at $p<0.05$. The calculations were performed on SPSS for Windows 8.0.1 (SPSS Inc., Chicago, IL, U.S.A.).

\section{RESULTS}

\section{Markers of Collagen Turnover}

PINP and ICTP. The PINP concentration was $2956 \pm 223$ $\mu \mathrm{g} / \mathrm{L}$, and the ICTP concentration was $153 \pm 7 \mu \mathrm{g} / \mathrm{L}$ (Table 2). Both concentrations were about 50 -fold higher than the mean 
concentrations for healthy adults (4), with a positive correlation between PINP and ICTP $(r=0.69 ; p=0.0001)$. A negative correlation existed between gestational age and PINP, and between gestational age and ICTP (Fig. 1), and positive correlations between birth weight SDS and PINP, and between birth weight SDS and ICTP (Fig. 1). In addition, the number of antenatal glucocorticoid treatments showed a negative correlation with ICTP ( $r=-0.23 ; p=0.04$; Fig. 2$)$ and cord artery base excess with PINP $(r=0.24 ; p=0.03)$. In preeclampsia, both the PINP and ICTP concentrations were lower (PINP $1895 \pm 386$ versus $3213 \pm 251 \mu \mathrm{g} / \mathrm{L}, p=0.005$; ICTP $109 \pm$ 14 versus $163 \pm 7 \mu \mathrm{g} / \mathrm{L}, p=0.002$ ), and in infants of mothers with chorioamnionitis ICTP, but not PINP, was higher (187 \pm 15 versus $144 \pm 8 \mu \mathrm{g} / \mathrm{L}, p=0.003)$. However, the associations with preeclampsia and chorioamnionitis did not remain significant in a multiple regression model (see Collagen Turnover and the IGF System). No correlation was observed with cord artery $\mathrm{pH}$ or placenta/infant weight ratio. A positive correlation existed between ICTP/PINP ratio and gestational age $(r=0.29 ; p=0.008)$ but not between ICTP/PINP ratio and other clinical data.

PIIINP. The PIIINP concentration in cord blood was $215 \pm$ $23 \mu \mathrm{g} / \mathrm{L}$ (Table 2), i.e. more than 50 -fold higher than the mean concentration for healthy adults (4). A negative correlation appeared between PIIINP and gestational age (Fig. 1). The PIIINP concentration was significantly higher in male than in
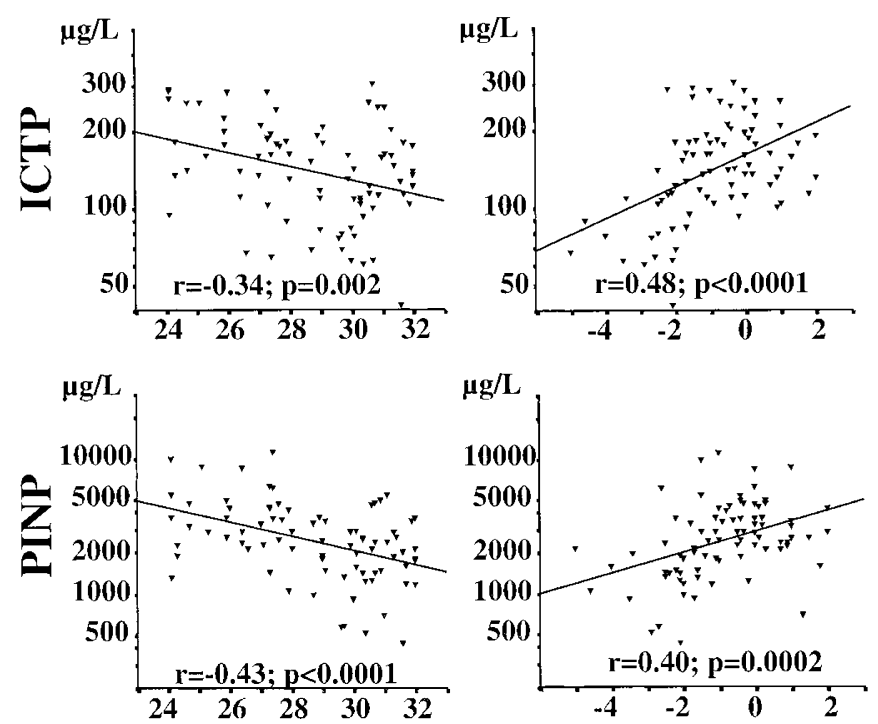

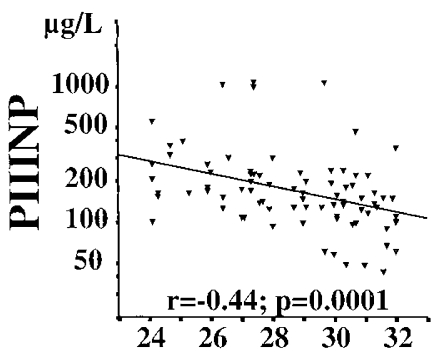

Gestational age

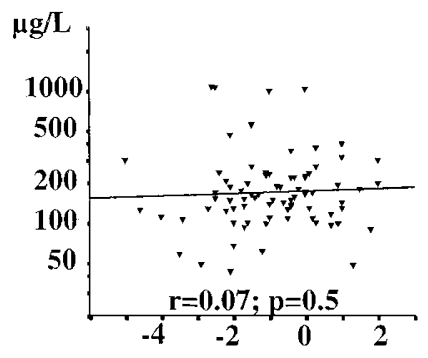

Birth weight SDS
Fig. 1. Correlation between markers of collagen turnover and gestational age and birth weight SDS. Correlation coefficients and $p$ values are indicated.
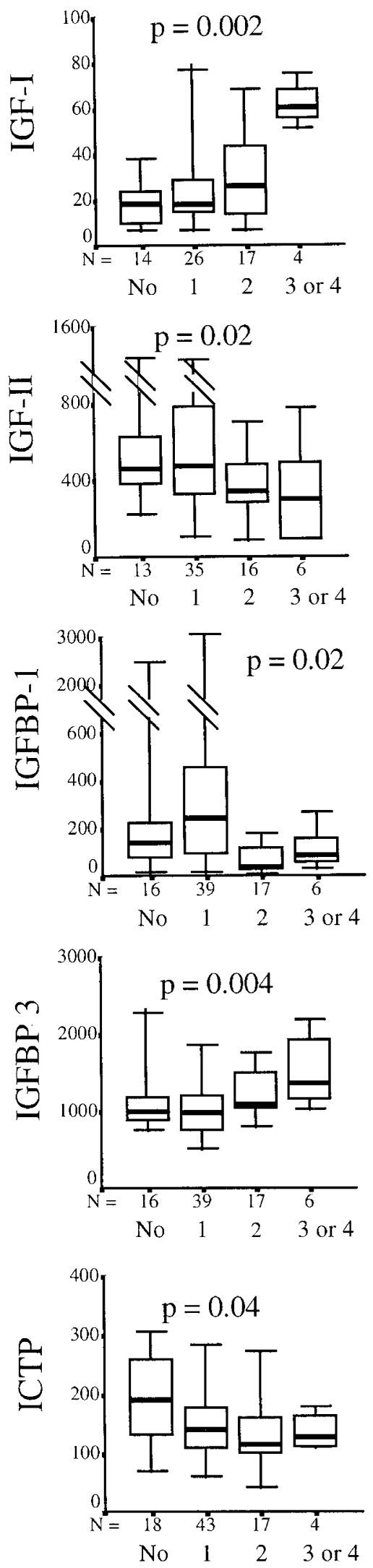

Fig. 2. Box plots (median, range, and interquartile values) of cord plasma IGF-I, IGF-II, IGFBP-1, IGFBP-3, and ICTP with regard to the number of maternal antenatal glucocorticoid treatments. $p$ values for linear trend are indicated. All associations remained significant also when adjusted for birth weight SDS, gestational age, and preeclampsia. 


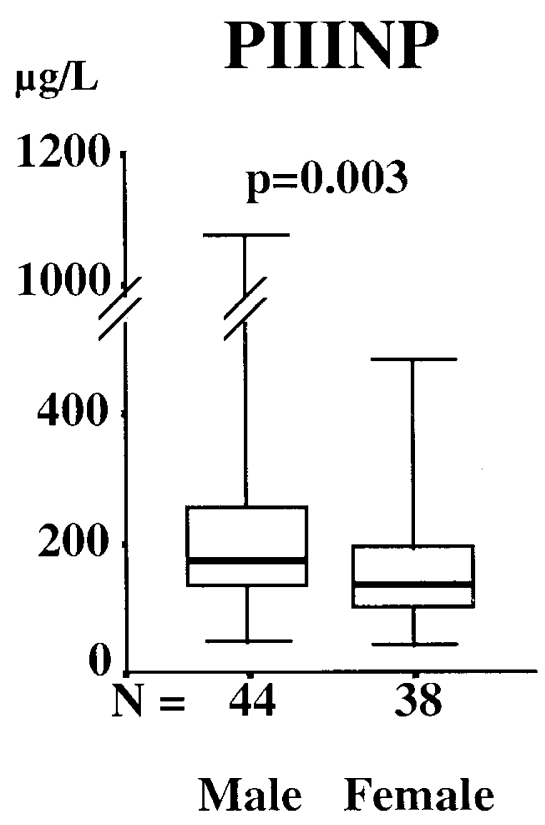

Fig. 3. Box plot (median, range, and interquartile values) of cord plasma PIIINP in male and female infants. $p$ value is indicated.

female infants (268 \pm 40 versus $154 \pm 14 \mu \mathrm{g} / \mathrm{L}$, respectively, $p=0.003$; Fig. 3). In multiple regression analysis, both gestational age $(\beta=-0.35 ; p=0.001)$ and $\operatorname{sex}(\beta=-0.25$; $p=0.02)$ remained significantly associated with PIIINP $\left(R^{2}=\right.$ 0.22 ). No interrelationships existed between PIIINP and birth weight SDS (Fig. 1) or any other clinical data.

\section{The IGF System}

IGF-I. The IGF-I concentration was $27.1 \pm 2.4 \mu \mathrm{g} / \mathrm{L}$ (Table 2). Correlations were positive between IGF-I and IGFBP-3 $(r=0.79 ; p<0.0001)$, and negative between IGF-I and IGFBP-1 $(r=-0.51 ; p=0.0002)$ and between IGF-I and IGF-II $(r=-0.45 ; p=0.001)$. In addition, a positive correlation existed between IGF-I and birth weight SDS (Fig. 4), but the association with gestational age was not statistically significant (Fig. 4). Moreover, there was a positive correlation between IGF-I and the number of antenatal glucocorticoid treatments $(r=0.38 ; p=0.002 ;$ Fig. 2$)$, as well as cord artery base excess $(r=0.35 ; p=0.007)$. In infants of mothers with preeclampsia, IGF-I was lower $(13.3 \pm 4.5$ versus $29.9 \pm 2.7$ $\mu \mathrm{g} / \mathrm{L}, p=0.002$; Fig. 5). There was no association with cord artery $\mathrm{pH}$, chorioamnionitis, or placenta/infant weight-ratio. When we performed multiple regression analysis to assess which clinical variables explained variation in IGF-I levels, birth weight SDS $(\beta=0.39 ; p<0.0001)$, number of antenatal glucocorticoid treatments $(\beta=0.33 ; p=0.001)$, preeclampsia $(\beta=-0.28 ; p=0.009)$, and cord artery base excess $(r=0.22$; $p=0.02)$ all remained significantly associated with IGF-I $\left(R^{2}=0.54\right)$.

IGF-II. The IGF-II concentration was $523 \pm 40 \mu \mathrm{g} / \mathrm{L}$ (Table 2). We found a negative correlation with birth weight SDS (Fig. 4) and the number of antenatal glucocorticoid treatments $(r=-0.28 ; p=0.02)$. No significant correlation appeared between IGF-II and IGFBP-1, IGFBP-3, gestational

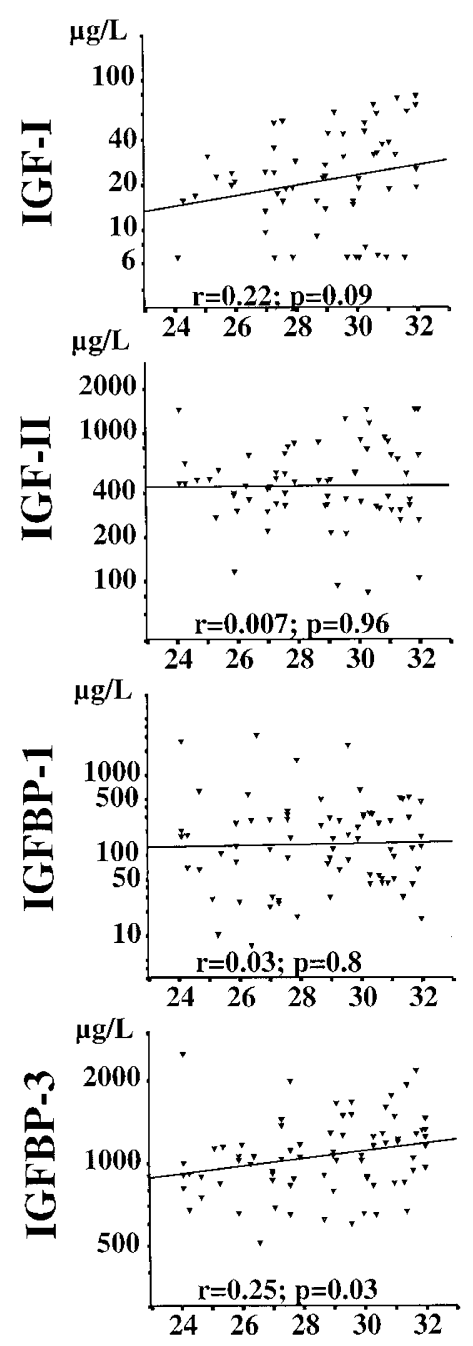

Gestational age
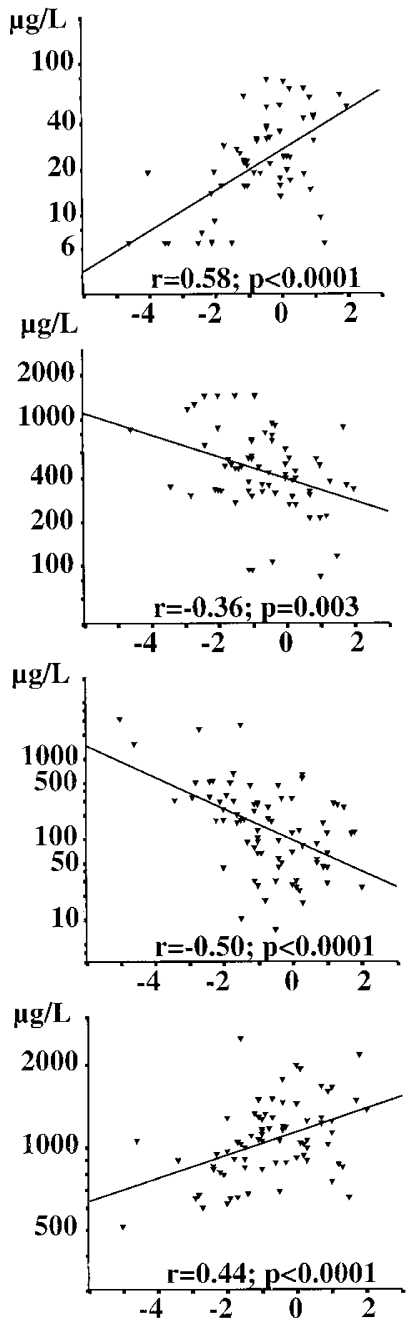

Birth weight SDS
Fig. 4. Correlation between IGF-I, IGF-II, IGFBP-1, and IGFBP-3 and gestational age and birth weight SDS. Correlation coefficients and $p$ values are indicated.

age (Fig. 4), or other clinical data. In multiple regression analysis, both birth weight SDS $(r=-0.34 ; p=0.003)$ and the number of glucocorticoid treatments $(r=-0.26 ; p=0.02)$ remained significantly associated with IGF-II $\left(R^{2}=0.19\right)$.

IGFBP-1. The IGFBP-1 concentration was $297 \pm 61 \mu \mathrm{g} / \mathrm{L}$ (Table 2), with no interrelationship with gestational age (Fig. 4) but a negative correlation with birth weight SDS (Fig. 4) and the number of antenatal glucocorticoid treatments $(r=-0.26$; $p=0.02$; Fig. 2). The IGFBP-1 concentration was higher in infants of mothers with preeclampsia $(551 \pm 180$ versus $255 \pm$ $63 \mu \mathrm{g} / \mathrm{L} ; p<0.0001$; Fig. 5), and in boys than in girls (415 \pm 112 versus $182 \pm 42 \mu \mathrm{g} / \mathrm{L} ; p=0.009)$. No correlation was apparent with cord artery base excess, chorioamnionitis, or placenta/infant weight-ratio. Four infants had very high IGFBP-1 concentrations $(1500-3100 \mu \mathrm{g} / \mathrm{L})$, the remaining IGFBP-1 concentrations being $<640 \mu \mathrm{g} / \mathrm{L}$. All these outliers were boys; three had a birth weight SDS below -2 SD, one's mother had preeclampsia, and none of them had a cord $\mathrm{pH}<$ 7.15 (one $\mathrm{pH}$ was unavailable). Considering that IGFBP-1 secretion is pulsatile with high amplitude $(23,24)$, we per- 


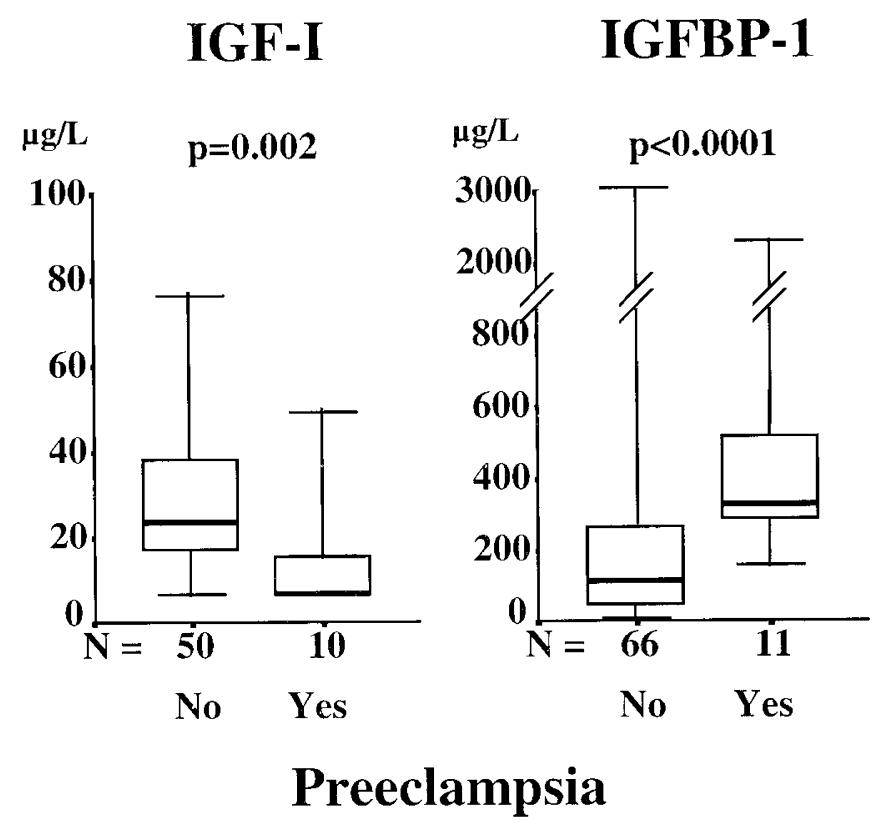

Fig. 5. Box plots (median, range, and interquartile values) of cord plasma IGF-I and IGFBP-1 in infants of mothers with and without preeclampsia. $p$ values are indicated.

formed another analysis after exclusion of these outliers. The significant inverse correlations remained between IGFBP-1 and birth weight SDS $(r=-0.35 ; p=0.002)$ and between IGFBP-1 and the number of antenatal glucocorticoid treatments $(r=-0.23 ; p=0.05)$. Moreover, IGFBP-1 remained significantly higher in infants of mothers with preeclampsia $(377 \pm 49$ versus $152 \pm 18 \mu \mathrm{g} / \mathrm{L} ; p<0.0001)$ and in boys compared with girls $(222 \pm 28$ versus $147 \pm 25 \mu \mathrm{g} / \mathrm{L} ; p=$ $0.02)$. In multiple regression analysis, preeclampsia $(\beta=0.42$; $p=0.0001)$ and the number of antenatal glucocorticoid treatments $(\beta=-0.24 ; p=0.02)$ remained significantly associated with IGFBP-1 $\left(R^{2}=0.23\right)$.

IGFBP-3. The IGFBP-3 concentration was $1110 \pm 42 \mu \mathrm{g} / \mathrm{L}$ (Table 2). A positive correlation with gestational age (Fig. 4), birth weight SDS (Fig. 4), and the number of antenatal glucocorticoid treatments $(r=0.33 ; p=0.004$; Fig. 2) were noted, and there was a negative correlation with placenta/infant weight-ratio $(r=-0.40 ; p=0.002)$. No significant association was found with any other clinical data. Multiple regression analysis indicated birth weight $\operatorname{SDS}(\beta=0.48 ; p<0.0001)$, gestational age $(\beta=0.33 ; p=0.002)$, and the number of antenatal glucocorticoid treatments $(r=0.30 ; p=0.004)$ as determinants that were significantly associated with IGFBP-3 $\left(R^{2}=0.49\right)$.

\section{Collagen Turnover and the IGF System}

Positive correlations were found between PINP and IGFBP-3, ICTP and IGFBP-3, PINP and IGF-I, and ICTP and IGF-I (Fig. 6). Negative correlations were found between IGFBP-1 and PINP $(r=-0.31 ; p=0.01)$, and IGFBP-1 and $\operatorname{ICTP}(r=-0.30 ; p=0.02)$. To study whether members of the IGF family may have been involved in the regulation of type I collagen turnover, we performed two separate stepwise multi-

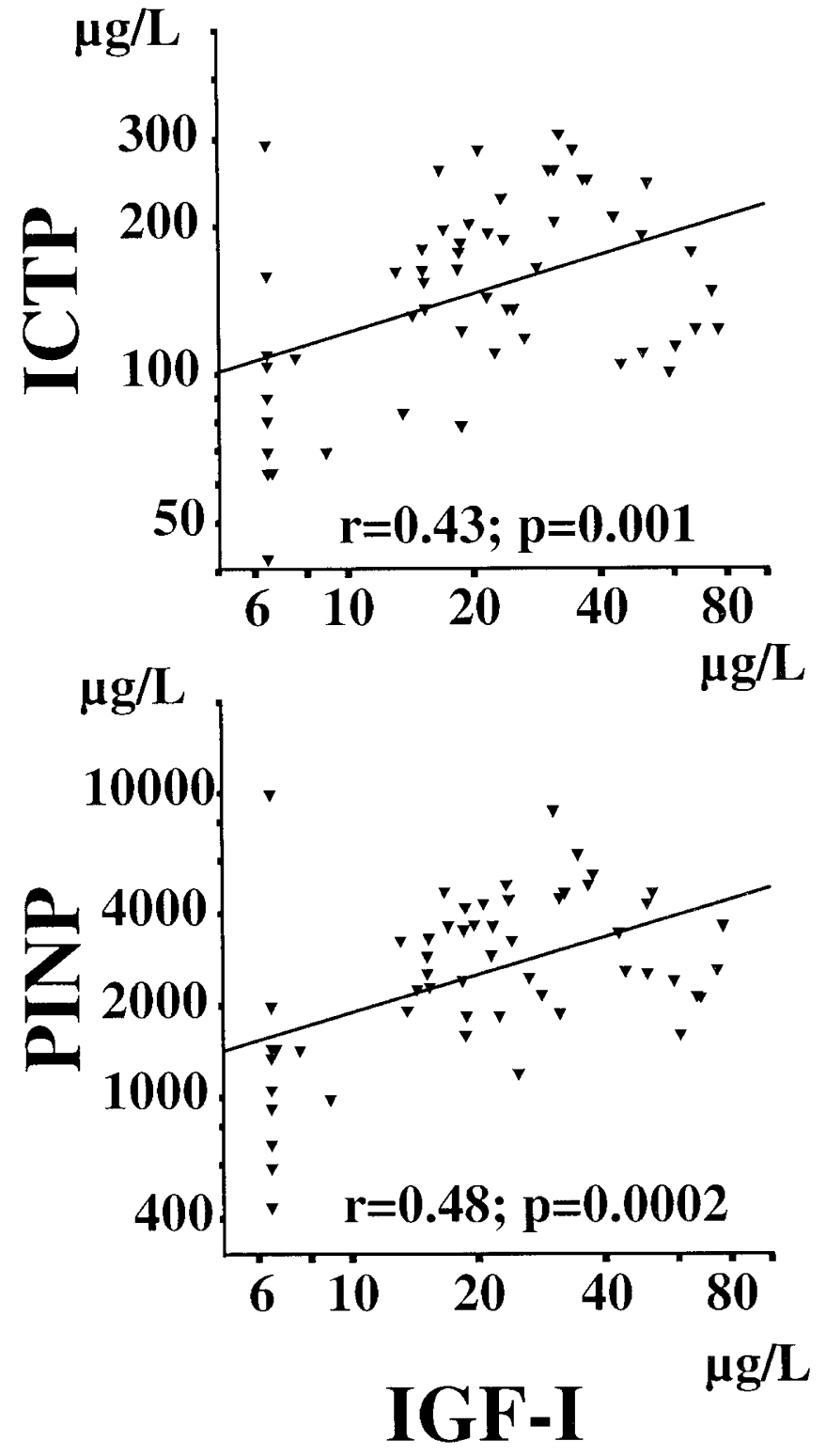

Fig. 6. Correlation between cord blood IGF-I and PINP and ICTP. Correlation coefficients and $p$ values are indicated. In multiple regression analysis, $47 \%$ of the variation in PINP was explained by gestational age and IGF-I $\left(R^{2}=0.47\right)$, and $54 \%$ of the variation in ICTP was explained by IGF-I, the number of maternal antenatal glucocorticoid treatments, and gestational age $\left(R^{2}=0.54\right)$.

ple regression analyses with either PINP or ICTP as dependent determinants; and IGF-I, IGFBP-1, IGFBP-3, and all clinical determinants with significant univariate correlation as independent determinants. Determinants that remained significantly associated with PINP $\left(R^{2}=0.47\right)$ were gestational age $(\beta=$ $-0.66 ; p<0.0001)$ and IGF-I $(\beta=0.52 ; p=0.0001)$. Determinants that remained significantly associated with ICTP $\left(R^{2}=0.54\right)$ were IGF-I $(\beta=0.61 ; p<0.0001)$, gestational age $(\beta=-0.58 ; p<0.0001)$, and the number of antenatal glucocorticoid treatments $(\beta=-0.30 ; p=0.02)$. Moreover, an inverse correlation appeared between the ICTP/PINP ratio and IGF-I $(r=-0.32 ; p=0.02)$, and this correlation was shown by multiple regression analysis to be independent of 
gestational age $(\beta=-0.41 ; p=0.002)$. No correlation existed between PIIINP and either IGF-I or IGF-II or IGFBP-1 or IGFBP-3.

\section{DISCUSSION}

We studied whether markers of type I and III collagen turnover in cord blood of premature infants are indicative of fetal growth and gestational age and whether they are related to changes in the fetal circulating IGF system during intrauterine growth. In addition, the study design enabled us to provide data on fetal collagen turnover and the IGF system in preeclampsia and after exposure to maternal antenatal glucocorticoids.

We found that cord plasma concentrations of PINP and ICTP were related to fetal growth, the levels being lower in infants smaller for their gestational age. We also demonstrated a trend toward a decrease in fetal PINP, ICTP, and PIIINP concentrations between 24 and $32 \mathrm{wk}$ of gestation. As hypothesized, fetal IGF-I is related to type I collagen turnover, reflected by concentrations of PINP and ICTP. In contrast, no such relationship emerged for type III collagen.

Our results show considerable turnover of type I collagen during fetal growth in late pregnancy. Disruptions of this turnover may take place in intrauterine growth restriction and impaired bone modeling in preterm infants, as recently suggested by another study (31). Reduced bone mineral content, resulting both from impaired bone modeling and dietary deficiency of minerals (38), is a well-recognized feature of intrauterine growth restriction and prematurity (39). In term infants, however, no difference in cord serum PICP and ICTP has been observed between SGA and AGA groups $(7,8)$. This difference may be related to different causes of growth retardation in preterm and full-term infants. In keeping with previous studies $(6,8,31,38)$, our results suggest that both type I collagen synthesis and degradation decrease with increasing gestational age, and the decrease in synthesis is even more rapid. It is of interest that type I collagen is also synthesized in the placenta (40), suggesting that placental collagen turnover may contribute to circulating PINP and ICTP. However, we found no association between PINP or ICTP and relative placental weight.

During childhood, one of the best single biochemical indicators of growth velocity is PIIINP $(11,41)$. During the second half of pregnancy, fetal PIIINP concentration mirrors the fetal growth velocity curve (9) and is lower in SGA than in AGA infants (10). Our data confirmed the inverse relationship between PIIINP and gestational age but, unexpectedly, we found no correlation between PIIINP and birth weight SDS. This may be because of differences in patient selection as the mean gestational age in our study was lower than in a previous study (10). Another reason may be that we used an intact PIIINP assay, which is more specific for the synthesis of type III procollagen than were the assays applied in previous studies (3). Therefore, in the preterm infants $<32$ wk of gestation, intact PIIINP may rather reflect developmental maturity, as indicated by gestational age.

In keeping with a previous study (9), the PIIINP concentration was found to be higher in male than in female infants. This finding could be explained by a possible sex-related difference in the body composition of the fetus, although in childhood the difference in body composition between boys and girls (42) is not accompanied by a similar difference in PIIINP concentrations (11).

The beneficial effect of maternal antenatal glucocorticoid treatment is well documented in reducing the neonatal morbidity and mortality of infants born before 32 wk of gestation (43). However, the use of multiple antenatal glucocorticoid treatments has raised concern about both short- and long-term side effects (44). In children and adults, markers of type I and III collagen turnover decrease during glucocorticoid treatment $(41,45)$. Our finding of a decreased ICTP after antenatal glucocorticoid treatment underlines the concerns of risks of repeated antenatal glucocorticoid treatments in respect of the possible effects on fetal collagen metabolism that may result in, for example, deviant bone modeling.

A novel finding of this study is an altered IGF and IGFBP profile associated with exposure to antenatal glucocorticoid treatment, especially with multiple treatments. The increase in IGF-I and IGFBP-3, as well as the decrease in IGFBP-1, may seem to be at variance with the role of glucocorticoids in reducing growth and increasing IGFBP-1 synthesis (46). Accordingly, healthy men receiving glucocorticoids show a similar pattern of changes, which is, however, associated with decreased IGF bioactivity (47). A point that makes our results especially intriguing is that glucocorticoids and the IGF system have been proposed to be key mediators of the fetal programming of adult cardiovascular disease (48). Further studies are required to elucidate whether the altered IGF and IGFBP profile indeed predicts long-term metabolic effects, but this finding emphasizes the importance of careful follow-up of children exposed to multiple antenatal glucocorticoid treatment in utero.

One of the major causes of intrauterine growth restriction is preeclampsia, characterized by chronic fetal hypoxia and inadequate nutrient supply (49). We found that even after adjustment for fetal size, infants of preeclamptic mothers showed lower cord plasma IGF-I and, in keeping with a previous study (22), higher cord plasma IGFBP-1. Chronic, rather then acute, fetal hypoxia has been shown to increase IGFBP-1 gene expression (46). Interestingly, in severe preeclampsia, IGFBP-1 at the fetomaternal interface is markedly elevated, supporting the hypothesis that elevated decidual levels of IGFBP-1 may control placental invasion by restricting the effects of placental IGFs $(20,50)$. Given this background, it is possible that the elevated fetal circulating IGFBP-1 levels reflect hypoxic regulation of IGFBP-1, a mechanism operating in the human fetus to restrict IGF-mediated intrauterine growth when nutritional conditions are inadequate. However, in infants with a low cord artery base excess, we found lower IGF-I but no difference in IGFBP-1. Low base excess nevertheless reflects fetal hypoxia during a few hours before birth, and the duration of hypoxia required to induce increased synthesis of IGFBP-1 may be longer (46). The origin of the fetal IGFBP-1 remains to be identified, the most likely source being the fetal liver (46).

The negative correlation between cord blood IGF-II and birth weight SDS was unexpected, because there are reports to 
the opposite $(12,16)$ or of no association at all $(13,14)$. However, our study includes the largest number of small premature infants so far reported using the same variables. IGF-II-encoding mRNA is abundant in the fetal adrenals and is stimulated by ACTH in fetal adrenal cortical cells (51). Because cord blood ACTH is higher in SGA infants (52), a link may exist between the IGF system and the fetomaternalplacental corticotropin-ACTH-adrenal cortex axis, which is activated also in preeclampsia (53). Given this background, our findings that IGF-II was lower in infants exposed to antenatal glucocorticoids and was not associated with preeclampsia show that, if it exists, the association between the IGF system and ACTH is very complex.

We found that preterm infants with higher IGF-I concentrations also had abundant type I collagen turnover, as indicated by elevated PINP and ICTP concentrations. Furthermore, these infants showed an increased rate of collagen synthesis compared with its degradation (low ICTP/PINP ratio). These results are in accordance with in vitro studies demonstrating the role of IGF-I in regulating type I collagen turnover and a recent study showing a similar relationship between IGF-I and PICP in preterm infants (31).

We thus conclude that in preterm infants, cord blood PINP and ICTP reflect both fetal growth pattern and maturity, and that fetal IGF-I may regulate fetal growth in part by influencing type I collagen turnover. Therefore, PINP and ICTP deserve being evaluated as potential indicators of postnatal growth velocity in small preterm infants. Intact PIIINP in these infants seems to be dependent on fetal maturity alone.

\section{REFERENCES}

1. Jones JI, Clemmons DR 1995 Insulin-like growth factors and their binding proteins: biological actions. Endocr Rev 16:3-34

2. Prockop DJ, Kivirikko KI, Tuderman L, Guzman NA 1979 The biosynthesis of collagen and its disorders. N Engl J Med 301:77-85

3. Risteli J, Risteli L 1995 Analysing connective tissue metabolites in human serum: biochemical, physiological and methodological aspects. J Hepatol 22:77-81

4. Risteli J, Risteli L 1999 Products of bone collagen metabolism. In: Seibel MJ, Robins SP, Bilezikian JP (eds) Dynamics of Bone and Cartilage Metabolism: Principles and Clinical Applications. Academic Press, London, pp 275-287

5. Ogueh O, Khastgir G, Studd J, Jones J, Alaghband-Zadeh J, Johnson MR 1998 The relationship of fetal serum markers of bone metabolism to gestational age. Early Hum Dev 51:109-112

6. Mora S, Prinster C, Bellini A, Weber G, Proverbio MC, Puzzovio M, Bianchi C, Chiumello G 1997 Bone turnover in neonates: changes of urinary excretion rate of collagen type I cross-linked peptides during the first days of life and influence of gestational age. Bone 20:563-566

7. Namgung R, Tsang RC, Sierra RI, Ho ML 1996 Normal serum indices of bone collagen biosynthesis and degradation in small for gestational age infants. J Pediatr Gastroenterol Nutr 23:224-228

8. Hytinantti T, Rutanen E-M, Turpeinen M, Sorva R, Andersson S 2000 Markers of collagen metabolism and insulin-like growth factor binding protein-1 in term infants. Arch Dis Child Fetal Neonatal Ed 83:F17-F20

9. Vanhaesebrouck P, Kint J, Dhont M, de Praeter C, Leroy J 1994 Aminoterminal propeptide of type III procollagen in cord blood and amniotic fluid of appropriatefor-gestational-age infants: a predictor of age-related fetal growth rate. Pediatr Res $36: 64-70$

10. Vanhaesebrouck P, Kint J, van Kets H, Govaert P, Smets K, Defoort P, Leroy J 1994 Aminoterminal propeptide of type III procollagen in cord blood and amniotic fluid of high-risk pregnancies: a biochemical approach to the dynamic assessment of deviant fetal growth. Pediatr Res 36:71-76

11. Trivedi P, Risteli J, Risteli L, Hindmarsh PC, Brook CG, Mowat AP 1991 Serum concentrations of type I procollagen propeptides as biochemical markers of growth velocity in healthy children and in children with growth disorders. Pediatr Res 30:276-280

12. Giudice LC, De Zegher F, Gargosky SE, Dsupin BA, de las Fuentes L, Crystal RA, Hintz RL, Rosenfeld RG 1995 Insulin-like growth factors and their binding proteins in the term and preterm human fetus and neonate with normal and extremes of intrauterine growth. J Clin Endocrinol Metab 80:1548-1555
13. Klauwer D, Blum WF, Hanitsch S, Rascher W, Lee PDK, Kiess W 1997 IGF-I, IGF-II, free IGF-I and IGFBP-1, -2 and -3 levels in venous cord blood: relationship to birthweight, length and gestational age in healthy newborns. Acta Pediatr 86:826833

14. Lassarre C, Hardouin S, Daffos F, Forestier F, Frankenne F, Bimoux M 1991 Serum insulin-like growth factors and insulin-like growth factor binding proteins in the human fetus: relationships with growth in normal subjects and subjects with intrauterine growth retardation. Pediatr Res 29:219-225

15. Leger J, Noel M, Limal JM, Czernichow P 1996 Growth factors and intrauterine growth retardation: II. Serum growth hormone, insulin-like growth factor (IGF) I, and IGF-binding protein 3 levels in children with intrauterine growth retardation compared with normal control subjects: prospective study from birth to two years of age. Pediatr Res 40:101-107

16. Verhaeghe J, van Bree R, van Herck E, Laureys J, Bouillon R, van Assche FA 1993 C-peptide, insulin-like growth factors I and II, and insulin-like growth factor binding protein-1 in umbilical cord serum: correlations with birth weight. Am J Obstet Gynecol 169:89-97

17. Östlund E, Bang P, Hagenäs L, Fried G 1997 Insulin-like growth factor I in fetal serum obtained by cordocentesis is correlated with intrauterine growth retardation. Hum Reprod 12:840-844

18. Hakala-Ala-Pietilä TH, Koistinen RA, Salonen RK, Seppälä MT 1993 Elevated second-trimester amniotic fluid concentration of insulin-like growth factor binding protein-1 in fetal growth retardation. Am J Obstet Gynecol 163:35-39

19. Seppälä M, Riittinen L, Julkunen M, Koistinen R, Wahlström T, Iino K, Alfthan H, Stenman UH, Huhtala ML 1988 Structural studies, localization in tissue and clinical aspects of human endometrial proteins. J Reprod Fertil Suppl 36:127-141

20. Giudice LC, Martina NA, Crystal RA, Tazuke S, Druzin M 1997 Insulin-like growth factor binding protein-1 at the maternal-fetal interface and insulin-like growth factor-I: insulin-like growth factor-II, and insulin-like growth factor binding protein-1 in the circulation of women with severe pre-eclampsia. Am J Obstet Gynecol 176:751758

21. Iino K, Sjöberg J, Seppälä M 1986 Elevated circulating levels of a decidual protein, placental protein 12, in preeclampsia. Obstet Gynecol 68:58-60

22. Wang HS, Lee JD, Cheng BJ, Soong YK 1996 Insulin-like growth factor-binding protein 1 and insulin-like growth factor-binding protein 3 in pre-eclampsia. Br J Obstet Gynaecol 103:654-659

23. Hamilton-Fairley D, White D, Griffits M, Anyaoku V, Koistinen R, Seppala M, Franks S 1995 Diurnal variation of sex hormone binding globulin and insulin-like growth factor binding protein-1 in women with polycystic ovary syndrome. Clin Endocrinol (Oxf) 43:159-165

24. Ogilvy-Stuart AL, Hands SJ, Adcock CJ, Holly JM, Matthews DR, Mohamed-Ali V, Yudkin JS, Wilkinson AR, Dunger B 1998 Insulin, insulin-like growth factor I (IGF-I), IGF-binding protein-1, growth hormone, and feeding in the newborn. J Clin Endocrinol Metab 83:3550-3557

25. Canalis E 1980 Effect of insulin-like growth factor I on DNA and protein synthesis in cultured rat calvaria. J Clin Invest 66:709-719

26. McCarthy TM, Centrella M, Canalis E 1989 Insulin-like growth factor and bone. Connect Tissue Res 20:277-281

27. Peterkofsky B, Gosiewska A, Gipp DE, Shah V, Wilson S 1994 Circulating insulinlike growth factor binding proteins (IGFBPs) 1 and 2 induced in vitamin-C deficient or fasted guinea pigs inhibit IGF-I action in cultured cells. Growth Factors 10:229241

28. Rechler MM 1993 Insulin-like growth factor binding proteins. Vitam Horm 47:1-114

29. Grinspoon SK, Baum HB, Peterson S, Klibanski A 1995 Effects of rhIGF-Iadministration on bone turnover during short-term fasting. J Clin Invest 96:900-906

30. Puistola U, Risteli L, Kauppila A, Knip M, Risteli J 1993 Markers of type I and type III collagen synthesis in serum as indicators of tissue growth during pregnancy. J Clin Endocrinol Metab 77:178-182

31. Seibold-Weiger K, Wollmann HA, Ranke MB, Speer CP 2000 Plasma concentrations of the carboxyterminal propeptide of type I procollagen (PICP) in preterm neonates from birth to term. Pediatr Res 48:104-108

32. Crofton PM, Shrivastava A, Wade JC, Stephen R, Kelnar CJH, Lyon JA, McIntosh N 1999 Bone and collagen markers in preterm infants: relationship with growth and bone mineral content over the first 10 weeks of life. Pediatr Res 46:581-587

33. Pihkala J, Hakala T, Voutilainen P, Raivio K 1989 Uudet suomalaiset sikiön kasvukäyrät [New Finnish fetal growth curves]. Duodecim 105:1540-1546

34. Sassi ML, Eriksen H, Risteli L, Niemi S, Mansell J, Goven M, Risteli J 2000 Immunochemical characterization of the assay for the carboxyterminal telopeptide of human type I collagen (ICTP): loss of antigenicity by treatment with cathepsin K. Bone 26:367-373

35. Harrela M, Koistinen H, Kaprio J, Lehtovirta M, Tuomilehto J, Eriksson J, Toivanen L, Koskenvuo M, Leinonen P, Koistinen R, Seppälä M 1996 Genetic and environmental components of interindividual variation in circulating levels of IGF-I, IGF-II, IGFBP-1 and IGFBP-3. J Clin Invest 98:2612-2615

36. Rutanen EM, Kärkkäinen T, Lehtovirta J, Uotila JT, Hinkula MK, Hartikainen AL 1996 Evaluation of a rapid striptest for insulin-like growth factor binding protein 1 in the diagnosis of ruptured fetal membranes. Clin Chim Act 253:91-101

37. Koistinen H, Seppälä M, Koistinen R 1994 Different forms of insulin-like growth factor binding-protein-3 detected in serum and seminal plasma by immunofluorometric assay with monoclonal antibodies. Clin Chem 40:531-536

38. Mora S, Weber G, Bellini A, Bianchi C, Chiumello G 1994 Bone modeling alteration in premature infants. Arch Pediatr Adolesc Med 148:1215-1217

39. Petersen S, Gotfredsen A, Knudsen FU 1989 Total body mineral in light-forgestational-age infants and appropriate-for-gestational-age infants. Acta Paediatr Scand 78:347-350 
40. Amenta PS, Gay S, Vaheri A, Martinez-Hernandez A 1986 The extracellular matrix is an integrated unit: ultrastructural localization of collagen types I, III, IV, V, VI, fibronectin, and laminin in human term placenta. Collagen Relat Res 6:125-152

41. Wolthers OD, Hansen M, Juul A, Nielsen HK, Pedersen S 1997 Knemometry, urine cortisol excretion, and measurements of insulin-like-growth-factor axis and collagen turnover in children treated with inhaled corticosteroids. Pediatr Res 41:44-50

42. Goran MI, Shewchuk R, Gower BA, Nagy TR, Carpenter WH, Johnson RK 1998 Longitudinal changes in fatness in white children: no effect of childhood energy expenditure. Am J Clin Nutr 67:309-316

43. Crowley PA 1995 Antenatal corticosteroid therapy: a meta-analysis of the randomized trials, 1972 to 1994 . Am J Obstet Gynecol 173:322-335

44. Lacaze-Masmonteil T, Audibert F 2000 Multiple courses of antenatal glucocorticoid treatment and fetal outcome. J Perinat Med 28:185-193

45. Oikarinen A, Autio P, Vuori J, Väänänen K, Risteli L, Kiistala U, Risteli J 1992 Systemic glucocorticoid treatment decreases serum concentrations of carboxyterminal propeptide of type I procollagen and aminoterminal propeptide of type III procollagen. Br J Dermatol 126:172-178

46. Tazuke SI, Mazure NM, Sugawara J, Carland G, Faessen GH, Suen LF, Irwin JC, Powell DR, Giaccia JA, Giudice LC 1998 Hypoxia stimulates insulin-like growth factor binding protein 1 (IGFBP-1) gene expression in HepG2 cells: a possible model for IGFBP-1 expression in fetal hypoxia. Proc Natl Acad Sci USA 95:10188-10193
47. Miell JP, Taylor AM, Jones J, Holly JM, Gaillard RC, Pralong FP, Ross RJ, Blum WF 1993 The effects of dexamethasone treatment on immunoreactive and bioactive insulin-like growth factors (IGFs) and IGF-binding proteins in normal male volunteers. J Endocrinol 136:525-533

48. Barker DJP, Gluckman PD, Godfrey KM, Harding JE, Owens JA, Robinson JS 1993 Fetal nutrition and cardiovascular disease in adult life. Lancet 341:938-941

49. Giudice LC, Mark SP, Irwin JC 1998 Paracrine actions of insulin-like growth factors and IGF binding protein-1 in non-pregnant human endometrium and at the decidualtrophoblast interface. J Reprod Immunol 39:133-148

50. Ritvos O, Ranta T, Jalkanen J, Suikkari AM, Voutilainen R, Bohn H, Rutanen EM 1988 Insulin-like growth factor (IGF) binding protein from human decidua inhibits the binding and biological action of IGF-I in cultured choriocarcinoma cell. Endocrinology 122:2150-2157

51. Voutilainen R, Miller WL 1988 Developmental and hormonal regulation of mRNAs for insulin-like growth factor II and steroidogenic enzymes in human fetal adrenals and gonads. DNA 7:9-15

52. Goland RS, Jozak S, Warren WB, Conwell IM, Stark RI, Tropper PJ 1993 Elevated levels of umbilical cord plasma corticotropin-releasing hormone in growth-retarded fetuses. J Clin Endocrinol Metab 77:1174-1179

53. Goland RS, Tropper PJ, Warren WB, Stark RI, Jozak SM, Conwell IM 1995 Concentrations of corticotropin-releasing hormone in the umbilical-cord blood of pregnancies complicated by pre-eclampsia. Reprod Fertil Dev 7:1227-1230 